\title{
Long-term risk of chronic kidney disease and mortality in children after acute kidney injury: a systematic review
}

\author{
Jason H Greenberg ${ }^{1,3}$, Steven Coca ${ }^{2,3}$ and Chirag R Parikh ${ }^{2,3^{*}}$
}

\begin{abstract}
Background: Acute kidney injury (AKI) is associated with significant short-term morbidity and mortality in children. However, the risk for long-term outcomes after AKI is largely unknown.

Methods: We performed a systematic review and meta-analysis to determine the cumulative incidence rate of proteinuria, hypertension, decline in glomerular filtration rate (GFR), and mortality after an episode of AKI. After screening 1934 published articles from 1985-2013, we included 10 cohort studies that reported long-term outcomes after AKI in children.

Results: A total of 346 patients were included in these studies with a mean follow-up of 6.5 years (range 2-16) after AKl. The studies were of variable quality and had differing definitions of AKI with five studies only including patients who required dialysis during an AKI episode. There was a substantial discrepancy in the outcomes across these studies, most likely due to study size, disparate outcome definitions, and methodological differences. In addition, there was no non-AKI comparator group in any of the published studies. The cumulative incidence rates for proteinuria, hypertension, abnormal GFR $\left(<90 \mathrm{ml} / \mathrm{min} / 1.73 \mathrm{~m}^{2}\right), \mathrm{GFR}<60 \mathrm{ml} / \mathrm{min} / 1.73 \mathrm{~m}^{2}$, end stage renal disease, and mortality per 100 patient-years were 3.1 (95\% Cl 2.1-4.1), 1.4 (0.9-2.1), 6.3 (5.1-7.5), 0.8 (0.4 -1.4), 0.9 (0.6-1.4), and 3.7 (2.8-4.5) respectively.
\end{abstract}

Conclusions: AKI appears to be associated with a high risk of long-term renal outcomes in children. These findings may have implications for care after an episode of AKI in children. Future prospective studies with appropriate non-AKI comparator groups will be required to confirm these results.

Keywords: Pediatrics, Acute kidney injury, Progression, Proteinuria, Hypertension, Chronic kidney disease, Long-term survival

\section{Background}

Pediatric acute kidney injury (AKI) is a significant health concern as its incidence has rapidly increased over the last 30 years [1,2]. The increased incidence of AKI disproportionately affects children with chronic medical diseases who are hospitalized frequently and now living longer lives. This represents a shift in the epidemiology of AKI, in which AKI is now more often associated with complications of a child's medical or surgical hospitalization compared to primary

\footnotetext{
* Correspondence: chirag.parikh@yale.edu

${ }^{2}$ Department of Internal Medicine, Section of Nephrology, New Haven, $C T$ and VA Medical Center, Yale University School of Medicine, West Haven, CT, USA

${ }^{3}$ Yale Program of Applied Translational Research, Yale University School of Medicine, 60 Temple Street, 6th Floor, Suite 6C, New Haven 06510, CT, USA Full list of author information is available at the end of the article
}

renal disease [3-7]. For hospitalized patients, AKI is independently associated with increased mortality and length of stay [8-11].

Until recently, AKI was considered a transient reversible syndrome. This paradigm has been refuted by a multitude of animal research and clinical studies. These studies support the hypothesis that an episode of AKI can cause permanent long-term kidney damage [12-14]. Animal studies have shown that AKI can lead to an irreversible reduction in peritubular capillaries causing hypoxia of renal parenchyma [15]. Additional studies show that AKI triggers molecular pathways that lead to prolonged cellular inflammation even after serum creatinine returns to baseline [16]. This inflammation contributes to fibrosis of the kidney and long-term renal dysfunction.

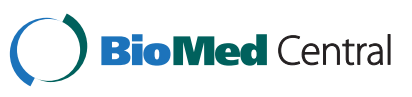


It is suggested that in humans as well, an episode of AKI causes renal inflammation and subsequent fibrosis that may result in chronic dysfunction $[17,18]$. Depending on the severity of inflammation and the site of injury within the kidney, the phenotype of chronic dysfunction may be in the form of proteinuria, hypertension, chronic kidney disease (CKD), or end stage renal disease (ESRD). Multiple observational studies in adult populations have shown that AKI is an independent risk factor for CKD, ESRD, and mortality [19-25]. A systematic review and meta-analysis by Coca et al. determined that the longterm risk of CKD and ESRD in adult patients after AKI is higher compared with patients without AKI, with hazard ratios of 8.8 (95\% CI 3.1-25.5) and 3.1 (95\% CI 1.95.0) respectively [20]. While this adult research is striking, it is not sufficient to understand whether AKI is an independent risk factor for CKD in children. This is because CKD risk factors, such as diabetes, coronary artery disease, hypertension, and smoking are more prevalent in adults and influence the development of clinical outcomes after AKI. In a way, the pediatric population is an ideal group to study the actual contribution of AKI as they have fewer of these CKD risk factors affecting outcomes. Children also have a longer life expectancy with a longer time to manifest some of the possible outcomes after an episode of AKI.

It is important to understand the contribution of pediatric AKI to long-term renal and non-renal outcomes. This is imperative since there are no established outpatient management guidelines after resolution of an AKI episode. A recent editorial by Askenazi proposed that after an AKI children should have follow-up within 1 month of hospital discharge, quarterly for two visits, and then annually for two years [26]. If CKD or proteinuria is identified, patients would then be followed every 1 to 12 months as dictated by the KDIGO CKD guidelines [27]. This frequency of follow-up in CKD patients is dictated by GFR, albuminuria, underlying comorbid conditions, disease state, and risk of progression [27]. Proper follow-up of pediatric AKI patients could allow for earlier identification of renal outcomes and instituting therapy to limit disease progression. This follow-up will be critical as more children with chronic diseases are living longer and developing multiple AKI episodes over time $[28,29]$. The goal of the present study was to conduct a systematic review of the published literature and estimate the risk for long-term sequelae of renal and non-renal outcomes after AKI.

\section{Methods}

We searched the MEDLINE and EMBASE databases using the following terms: acute kidney injury (explode), AKI, ARF, chronic renal insufficiency (explode), chronic renal failure (explode), CKD, chronic disease, treatment outcome, follow-up studies, survival rate, quality of life, kidney injuries, and acute disease (refer to the on-line supplementary search strategy in Additional file 1 for a list of the search terms used). We also searched SCOPUS and the reference list of all reviewed articles to identify other eligible studies.

Studies were eligible for inclusion based upon the following criteria: 1) published from January 1985 onward; 2) mean outpatient follow-up after the episode of AKI was greater than 1 year; 3 ) pediatric cohort including patients aged 0-18 years at the time of AKI; 4) estimated GFR or measured GFR reported at a long-term follow-up visit. Data on proteinuria, hypertension, ESRD, or mortality as part of the follow-up data were also recorded. If a study had multiple time points when long-term follow-up data was obtained, the data from the last follow-up visit was used. There was no language restriction. Each article chosen by the primary reviewer was reviewed by a second reviewer to confirm eligibility.

Studies were excluded if they reported on fewer than 10 patients at the time of follow-up. We also excluded studies that exclusively focused on neonates or studies that had a majority of patients with primary renal disease (e.g. hemolytic-uremic syndrome, post-infectious acute glomerulonephritis).

\section{Data abstraction}

Data was extracted by using a standardized data extraction form. The reviewers extracted data about characteristics of participants (number, age, and sex), clinical setting, type of study (prospective versus retrospective), dates of enrollment, definition of AKI, definition of CKD, and rate of the outcomes (proteinuria, CKD, hypertension, ESRD, mortality) in participants with AKI. Methodological quality was assessed using the Cochrane Collaboration risk of bias guidelines [30].

\section{Outcome measures and statistical analysis}

Primary outcome measures were long-term cumulative incidence rate of proteinuria, hypertension, abnormal GFR $\left(<90 \mathrm{ml} / \mathrm{min} / 1.73 \mathrm{~m}^{2}\right), \mathrm{GFR}<60 \mathrm{ml} / \mathrm{min} / 1.73 \mathrm{~m}^{2}$, end stage renal disease, and mortality. Abnormal GFR was also used as an outcome in addition to GFR $<60 \mathrm{ml} / \mathrm{min} / 1.73 \mathrm{~m}^{2}$ because many studies used abnormal GFR as a primary outcome without specifying the GFR of each patient.

For each clinical outcome the cumulative incidence rate per 100 patient-years of follow-up was calculated. To determine this rate we used the number of events as our numerator and the number of patient-years of follow-up as our denominator. If there was no outcome data on the patients who were not enrolled from the original hospitalized cohort, we excluded these patients in our patientyears calculation. We also reported the pooled incidence of each outcome which designates the frequency of each 
specific long-term outcome. Both cumulative incidence rate and pooled incidence are weighted values.

\section{Results}

We identified 1934 citations from our MEDLINE and EMBASE online search and excluded 1882 citations based on the review of title and abstract. Full texts and reference lists for 52 articles were examined and 10 studies were included in the systematic review (Figure 1). The characteristics of the 10 studies included are described in Table 1. All of the primary studies reported on renal outcomes in children after discharge from a hospitalization during which they had an episode of AKI. All 10 studies were cohort studies and only one was conducted prospectively. Five of the studies enrolled hospitalized children with any stage of AKI and the other five only enrolled patients who required renal replacement therapy (RRT). Two studies reported on outcomes in AKI associated with cardiac surgery.

The 10 studies representing 8 different countries enrolled 346 patients. Six different definitions of AKI were used (Table 2). 60\% (range 17-100\%) of patients were enrolled from the surviving hospitalized cohort. Three of the primary studies excluded patients with pre-existing renal disease and the other 7 studies did not mention whether these patients were included or excluded. Longterm follow-up was also variable and was conducted from 2 years to 16 years after the episode of AKI, with a mean time of follow-up of 6.5 years. The outcome definitions and method of assessment for each primary studies is listed in Table 3.

A mean of $44 \%$ (range $17-100 \%$ ) of the patients in the detailed follow-up cohort were acutely dialyzed for their AKI episode. 9 studies reported on the acute inpatient mortality of patients which averaged to $24 \%$ (range 9$68 \%$ ) of patients dying with their acute illness.

\section{Proteinuria after AKI}

The outcomes for each study are reviewed in Table 2 . Eight studies reported on proteinuria. Multiple definitions of proteinuria were used in the primary studies (Table 3 ). Proteinuria was most commonly defined by a spot urine albumin to urine creatinine ratio greater than or equal to $30 \mathrm{mg} / \mathrm{g}$ or $2+$ protein on urine dipstick. The rate of proteinuria was 3.1 per 100 person-years (95\% CI 2.1-4.1) and the pooled incidence was $13.2 \%$ (95\% CI 8.9-17.5\%).

\section{Hypertension after AKI}

Nine studies reported on hypertension. Hypertension was most commonly defined as repeated systolic or diastolic blood pressures greater than the $95^{\text {th }}$ percentile for age, gender, and height. The rate of hypertension after AKI was 1.4 per 100 person-years (CI 0.9-2.1) and the pooled incidence was $6.6 \%$ (CI 3.8-9.4\%).

\section{Decline in GFR after AKI}

All of the ten studies reported on abnormal GFR. In 8 of the 10 studies abnormal GFR was defined as a GFR < $90 \mathrm{ml} / \mathrm{min} / 1.73 \mathrm{~m}^{2}$. Six different methods of estimating GFR were used, with 6 studies using the Schwartz formula (see Table 3) [31-35]. The rate of abnormal GFR was 6.3 per 100 person-years (CI 5.1-7.5) and the pooled incidence was $28.0 \%$ (CI 23.2-32.7\%). Nine studies reported on the number of patients who developed CKD with a GFR $<60 \mathrm{ml} / \mathrm{min} / 1.73 \mathrm{~m}^{2}$ after AKI, which was 0.8 per 100 person-years (CI 0.4-1.4) and the pooled incidence was $3.6 \%$ (CI 1.5-5.7\%). Eight studies reported on ESRD at follow-up, which was 0.9 per 100 personyears (CI 0.6-1.4) and the pooled incidence was $0.4 \%$ (CI $0-0.9 \%)$. The pooled rate of impaired GFR and ESRD after AKI was 7.2 per 100 person-years.

\section{Long-term mortality after AKI}

Six studies reported on patients who had died after hospital discharge. The cumulative incidence rate of mortality was 3.7 per 100 person-years (CI 2.8-4.5) and the pooled incidence was $17.6 \%$ (CI 13.6-21.6\%). As there was no comparator group within the studies, we compared long-term mortality rates after AKI with mortality rates of other

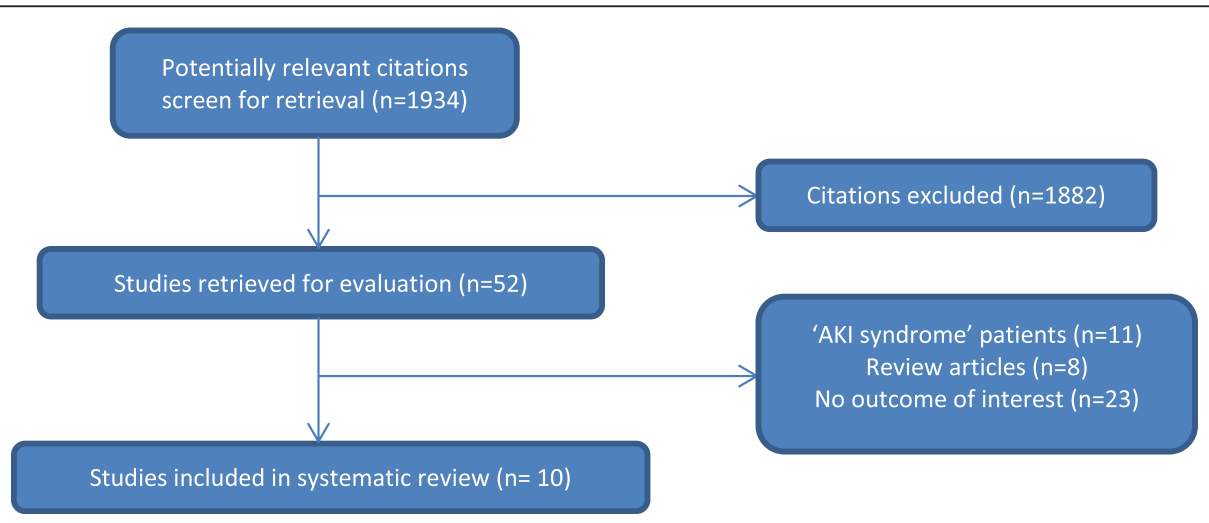

Figure 1 Selection of studies. 
Table 1 Characteristics of long-term follow-up studies of pediatric Acute Kidney Injury (AKI)

\begin{tabular}{|c|c|c|c|c|c|c|c|c|c|}
\hline Author, Year published & Country & Site & Study type & Setting & Severity & Episode of AKI & Age range of AKI & Mean F/U(y) & Mean age at $F / U(y)$ \\
\hline Askenazi [14], 2006 & USA & SC & $R$ & Hospitalized & Mixed AKI & $1998-2001$ & $6.4 y^{\sigma}$ & 4 & 9.8 \\
\hline Buysse [50], 2008 & Netherlands & SC & $\mathrm{R}$ & Meningitis & Mixed AKI & $1988-2001$ & $0.7-13.5 y$ & 10 & 15.9 \\
\hline Georgaki-Angelaki [45], 1989 & U.K. & SC & $\mathrm{R}$ & Hospitalized & RRT & $1971-1975$ & $3 d-10 y$ & 10 & 13 \\
\hline Mammen [41], 2012 & Canada & SC & $P$ & Hospitalized & Mixed AKI & $2006-2008$ & $0-18 y$ & $2^{*}$ & $3.0^{*}$ \\
\hline Mel [36], 2013 & Israel & SC & R & Cardiac surgery & PD & $1996-2004$ & $0.12 y^{\sigma}$ & $5^{*}$ & 8.4 \\
\hline Miler, 1997 & Poland & SC & $R$ & Hospitalized & Mixed AKI & $1980-1990$ & $3 d-5 y$ & 6 & - \\
\hline Shaw [44], 1991 & U.K. & SC & $\mathrm{R}$ & Cardiac surgery & RRT & $1983-1988$ & $2 d-2.5 y$ & 3 & 4.5 \\
\hline Slack [51], 2005 & U.K. & $M C$ & R & Meningitis & RRT & $1996-1999$ & $0.5-15 y$ & $4^{*}$ & 9.7 \\
\hline Viaud [46], 2011 & France & SC & $\mathrm{R}$ & Hospitalized & RRT & $1989-1996$ & $1-14 y$ & $16^{*}$ & $21^{*}$ \\
\hline Wedekin [52], 2008 & Germany & SC & R & Hospitalized Infant & Mixed AKI & $1997-2003$ & $0-1 y$ & $3^{*}$ & - \\
\hline
\end{tabular}

Abbreviations: PD, peritoneal dialysis, RRT, renal replacement therapy, SC, single center, MC, multi-center, R, retrospective, P, prospective, d, days, $y$, years, F/U, follow-up, Mixed AKI, encompasses all types of AKI: mild AKI, severe AKI, and AKI requiring RRT, $\sigma$, no range available; only median age provided, ${ }^{*}$, median. 
Table 2 Long-term outcome studies of pediatric Acute Kidney Injury (AKI)

\begin{tabular}{|c|c|c|c|c|c|c|c|c|c|c|c|c|c|}
\hline \multirow{3}{*}{$\begin{array}{l}\text { Author, Year } \\
\text { published }\end{array}$} & \multirow{3}{*}{$\begin{array}{l}\text { AKI } \\
\text { definition }\end{array}$} & \multirow{2}{*}{\multicolumn{2}{|c|}{ Hospitalized cohort }} & \multicolumn{10}{|c|}{ Detailed follow-up cohort } \\
\hline & & & & \multirow[b]{2}{*}{$\begin{array}{l}\text { Enrolled } \\
(\%)\end{array}$} & \multirow[b]{2}{*}{$\begin{array}{l}\text { Mean } \\
\text { follow-up } \\
\text { (years) }\end{array}$} & \multirow[b]{2}{*}{$\begin{array}{l}\text { Long-term } \\
\text { mortality, (\%) }\end{array}$} & \multirow[b]{2}{*}{$\begin{array}{l}\text { \# of Patients } \\
\text { with follow-up }\end{array}$} & \multirow[b]{2}{*}{$\begin{array}{l}\text { Abnormal GFR } \\
\text { definition }\end{array}$} & \multicolumn{5}{|c|}{ Outcomes (\%) } \\
\hline & & $\begin{array}{l}\text { HospitalMortality, } \\
\text { (\%) }\end{array}$ & $\begin{array}{l}\text { Acutely dialyzed } \\
\text { during hospitalization (\%) }\end{array}$ & & & & & & $\begin{array}{l}\text { Abnormal } \\
\text { GFR }\end{array}$ & $\begin{array}{l}\text { GFR } \\
<60\end{array}$ & ESRD & Proteinuria & HTN \\
\hline $\begin{array}{l}\text { Askenazi [14], } \\
2006\end{array}$ & eGFR $<75$ & $71 / 245,(29)$ & 21 & 17 & 4 & $35 / 174,(20)$ & 29 & GFR $<90$ & 14 & 7 & 9 & 28 & 21 \\
\hline $\begin{array}{l}\text { Buysse [50], } \\
2008\end{array}$ & $\begin{array}{l}\triangle \mathrm{SCr} \\
100 \%\end{array}$ & $\ldots$ & 25 & 71 & 10 & $\ldots$ & 16 & GFR $<90$ & 6 & 0 & 0 & 19 & 13 \\
\hline $\begin{array}{l}\text { Georgaki- } \\
\text { Angelaki [45], } \\
1989\end{array}$ & RRT & 17/70, (24) & 100 & 19 & 10 & $\ldots$ & 10 & GFR $<90$ & 20 & 0 & $\ldots$ & 0 & 0 \\
\hline $\begin{array}{l}\text { Mammen } \\
{[41], 2012}\end{array}$ & $\begin{array}{l}\text { AKIN } \\
\text { criteria }\end{array}$ & 40/425, (9) & 17 & 33 & $2^{*}$ & $\ldots$ & 126 & GFR $\leq 90$ & 39 & 1 & 0 & 10 & 3 \\
\hline $\begin{array}{l}\text { Mel [36], } \\
2013\end{array}$ & RRT & 35/76, (46) & 100 & 61 & $5^{*}$ & $15 / 41,(37)$ & 25 & GFR $<90$ & 4 & 0 & 0 & 0 & 0 \\
\hline Miler, 1997 & $A K l^{\Omega}$ & 28/118, (24) & 34 & 67 & 6 & $4 / 64,(6)$ & 60 & GFR $<90$ & 46 & 6 & 0 & $\ldots$ & 3 \\
\hline $\begin{array}{l}\text { Shaw [44], } \\
1991\end{array}$ & RRT & $23 / 34,(68)$ & 100 & 100 & 3 & $0 / 11,(0)$ & 11 & $\begin{array}{l}\text { abnormal } \\
\text { mGFR }\end{array}$ & 9 & 0 & 0 & 0 & 9 \\
\hline $\begin{array}{l}\text { Slack [51], } \\
2005\end{array}$ & RRT & 6/21, (29) & 100 & 80 & $4^{*}$ & $\ldots$ & $12^{\beta}$ & GFR $<90$ & 25 & 8 & 0 & 17 & 25 \\
\hline $\begin{array}{l}\text { Viaud [46], } \\
2011\end{array}$ & RRT & 16/52, (30) & 100 & 36 & $16^{*}$ & 0/36, (0) & 13 & GFR $<90$ & 61 & 23 & 0 & 54 & 15 \\
\hline $\begin{array}{l}\text { Wedekin [52], } \\
2008\end{array}$ & $\mathrm{SCr}>1.1$ & 26/70, (37) & 17 & 100 & $3^{*}$ & $7 / 44(16)$ & 44 & abnormal SCr & 0 & $\ldots$ & $\ldots$ & & $\ldots$ \\
\hline
\end{tabular}

The original hospitalized cohort is described along with the detailed follow-up cohort. The detailed follow-up cohort was assessed for long-term outcomes. Abbreviations: $h$, hour, RRT, renal replacement therapy, GFR, glomerular filtration rate $\left(\mathrm{ml} / \mathrm{min} / 1.73 \mathrm{~m}^{2}\right)$, SCr, serum creatinine (in mg/dl. $1 \mathrm{mg}, \mathrm{HTN}$, hypertension, UOP, urine output, AKIN criteria, Acute Kidney Injury Network classification system: $\Delta \mathrm{SCr}>0.3 \mathrm{mg} / \mathrm{dL}$ in $48 \mathrm{~h}, \Delta \mathrm{SCr}$ $\geq 50 \%$, or UOP $<0.5 \mathrm{ml} / \mathrm{kg} / \mathrm{hr} \times 6 \mathrm{~h}, \Omega$, AKI diagnosed by "generally accepted criteria", F/U, follow-up, ...,not available, $\beta$, only patients with abnormal SCr at PICU discharge were followed, Enrolled (\%) = \# of patients with follow-up/\# of patients who survived AKI admission, ${ }^{*}$, median. 
Table 3 Definition and method of attainment of study outcomes

\begin{tabular}{|c|c|c|c|c|c|c|}
\hline $\begin{array}{l}\text { Author, Year } \\
\text { published }\end{array}$ & $\begin{array}{l}\text { Proteinuria } \\
\text { definition }\end{array}$ & Proteinuria method & Hypertension definition & $\begin{array}{l}\text { Hypertension } \\
\text { method }\end{array}$ & $\begin{array}{l}\text { Abnormal GFR } \\
\text { definition }\end{array}$ & $\begin{array}{l}\text { GFR estimation } \\
\text { method }\end{array}$ \\
\hline Askenazi [14], 2006 & $\begin{array}{l}\text { Urine alb/UCr ratio } \\
>30 \mathrm{mg} / \mathrm{g}\end{array}$ & NS & $\begin{array}{l}\text { sys or dia }>95 \% \text { for age, sex, ht. HTN confirmed with } \\
2 \text { repeat visits }\end{array}$ & NS & GFR $<90$ & Schwartz formula \\
\hline Buysse [50], 2008 & $\begin{array}{l}\text { UPr/UCr }>0.2 \mathrm{mg} / \\
\mathrm{mg}\end{array}$ & Avg of 3 first morning samples & sys $>95 \%$ for age, sex, ht & $\begin{array}{l}\text { Avg of } 3 \mathrm{BP} \\
\text { measurements }\end{array}$ & GFR $<90$ & $\begin{array}{l}\text { Schwartz or Cockroft } \\
\text { formula }\end{array}$ \\
\hline $\begin{array}{l}\text { Georgaki-Angelaki } \\
\text { [45], } 1989\end{array}$ & NS & dipstick & abnormal BP for age & NS & GFR $<90$ & Inulin Clearance \\
\hline Mammen [41], 2012 & $\begin{array}{l}\text { Urine alb/UCr } \\
\text { ratio } \geq 30 \mathrm{mg} / \mathrm{g}\end{array}$ & $\begin{array}{l}\text { Spot collection. If positive, first } \\
\text { morning sample }\end{array}$ & $\begin{array}{l}\text { sys or dia }>95 \% \text { for age, sex, ht. HTN confirmed with } \\
\text { ABPM or } 2 \text { repeat visits }\end{array}$ & $\begin{array}{l}\text { lowest of } 3 \mathrm{BP} \\
\text { readings }\end{array}$ & $\mathrm{GFR} \leq 90$ & $\begin{array}{l}\text { Schwartz formula or } \\
\text { DTPA clearance }\end{array}$ \\
\hline Mel [36], 2013 & NS & Urinalysis & $\mathrm{BP}>90 \%$ & NS & GFR $<90$ & Schwartz formula \\
\hline Miler, 1997 & NS & NS & NS & NS & GFR $<90$ & Schwartz formula \\
\hline Shaw [44], 1991 & NS & dipstick & $\begin{array}{l}\text { sys or dia }>95 \% \text { for age, sex, ht. HTN confirmed with } \\
2 \text { repeat visits }\end{array}$ & NS & $\begin{array}{l}\text { Abnormal } \\
\text { mGFR }\end{array}$ & DTPA clearance \\
\hline Slack [51], 2005 & $>150$ mg/day & 24 hour collection & sys $>95 \%$ for age, sex, ht & $\begin{array}{l}\text { lowest of } 3 \mathrm{BP} \\
\text { readings }\end{array}$ & GFR $<90$ & EDTA clearance \\
\hline Viaud [46], 2011 & $\begin{array}{l}\mathrm{UPr} / \mathrm{UCr}>0.5 \mathrm{mg} / \\
\mathrm{mg}\end{array}$ & NS & NS & NS & GFR $<90$ & EDTA clearance \\
\hline Wedekin [52], 2008 & NP & NP & NP & NP & abnormal SCr & Schwartz formula \\
\hline
\end{tabular}

Abbreviations: Alb albumin, UCr urine creatinine, UPr urine protein, NS not specified, Avg average, NP not performed, sys systolic, dia diastolic, HTN hypertension, ht height, BP blood pressure, DTPA diethylenetriamine pentaacetate, EDTA ethylenediaminetetraacetic acid, ABPM ambulatory blood pressure monitoring, $S C r$ serum creatinine. 
pediatric cohorts detailed in Figure 2. We included a cohort of patients evaluated three years after discharge from the PICU, a meta-analysis of hemolytic uremic syndrome survivors evaluated after a mean follow-up of 4.4 years, survivors of Ewing sarcoma evaluated after 25 years, and the general pediatric population mortality rate (Figure 2) [14,15,36-39]. The AKI long-term mortality rate depicted in Figure 2 was comparable to the mortality rates found in other pediatric cohorts, but higher than the mortality rate of the general pediatric population [40]. Long-term event rates after AKI are displayed in Figure 3.

\section{Discussion}

This is the first systematic review and meta-analysis evaluating the long-term outcomes after pediatric AKI. We calculated the cumulative incidence rates and pooled incidence of long-term kidney complications such as proteinuria, hypertension, abnormal GFR, CKD, and ESRD after an episode of AKI. None of the studies included a control group that would allow us to understand the attributable risk of these complications that would be related to AKI. The long-term risk of mortality after AKI was also high when compared with the general pediatric population. While some of the renal outcomes may be attributed to the fact that these children are sicker with many subsequent hospitalizations and comorbidities, it is likely that the episode of AKI itself is associated with permanent renal damage and progressive decline in kidney function.

As mentioned previously, experimental studies in animals describe several mechanisms by which AKI may cause long-term sequelae, as it induces hypoxia, inflammation, and fibrosis [12-16]. These studies suggest that AKI may play a causal role in subsequent renal outcomes. Multiple studies in adults have included control groups and demonstrate that AKI is an independent risk factor for renal outcomes [19-23]. The incidence rates of renal outcomes estimated in the adult literature are higher compared to our findings [20]. The systematic review by Coca et al. reported rates of CKD, ESRD, and mortality of 25.8 per 100 patient-years (range 3.4-72.2), 8.6 per 100 patient-years (range $0.63-28.1$ ), and 16.8 per

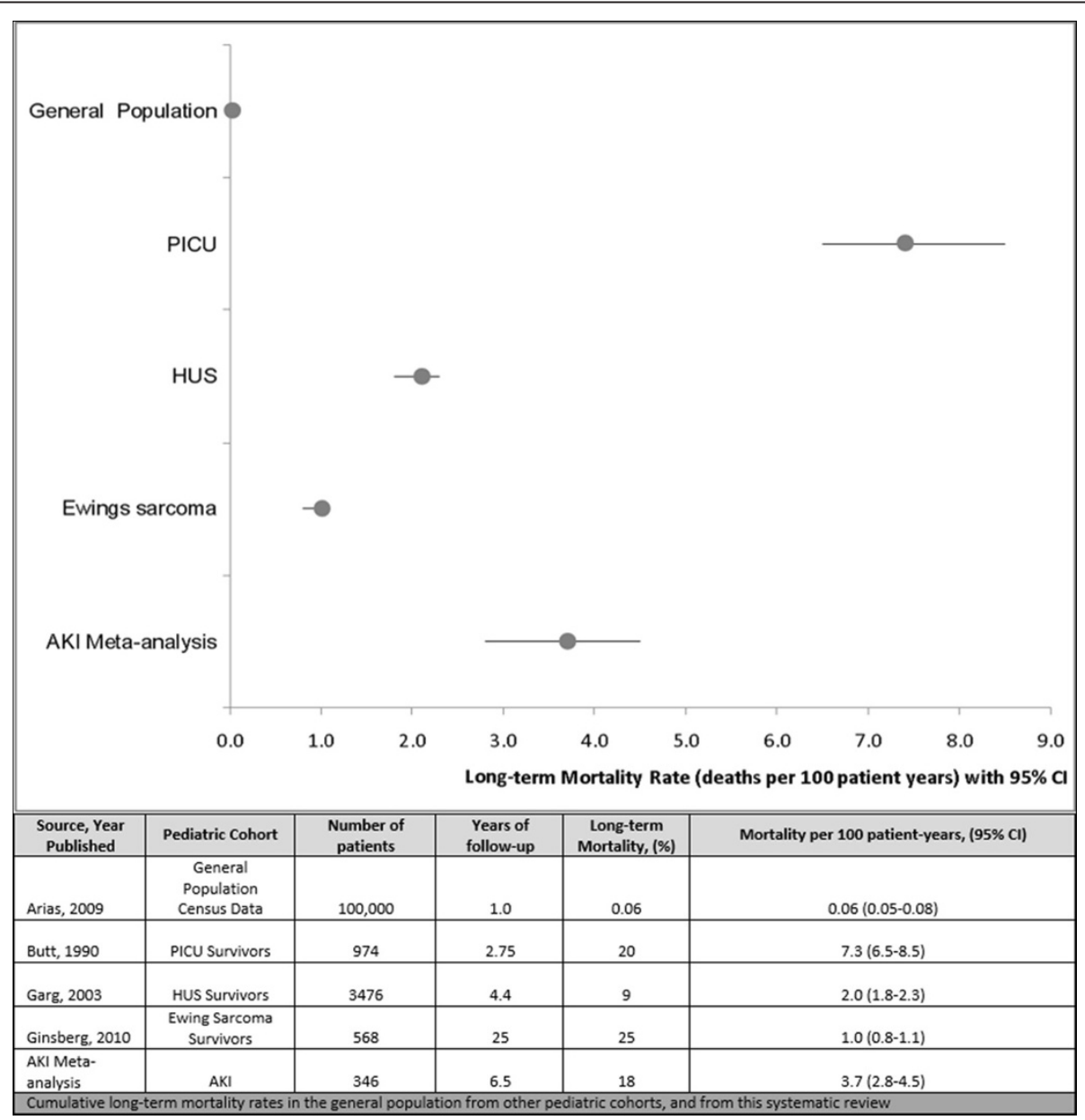

Figure 2 Long-term mortality in various pediatric cohorts. 


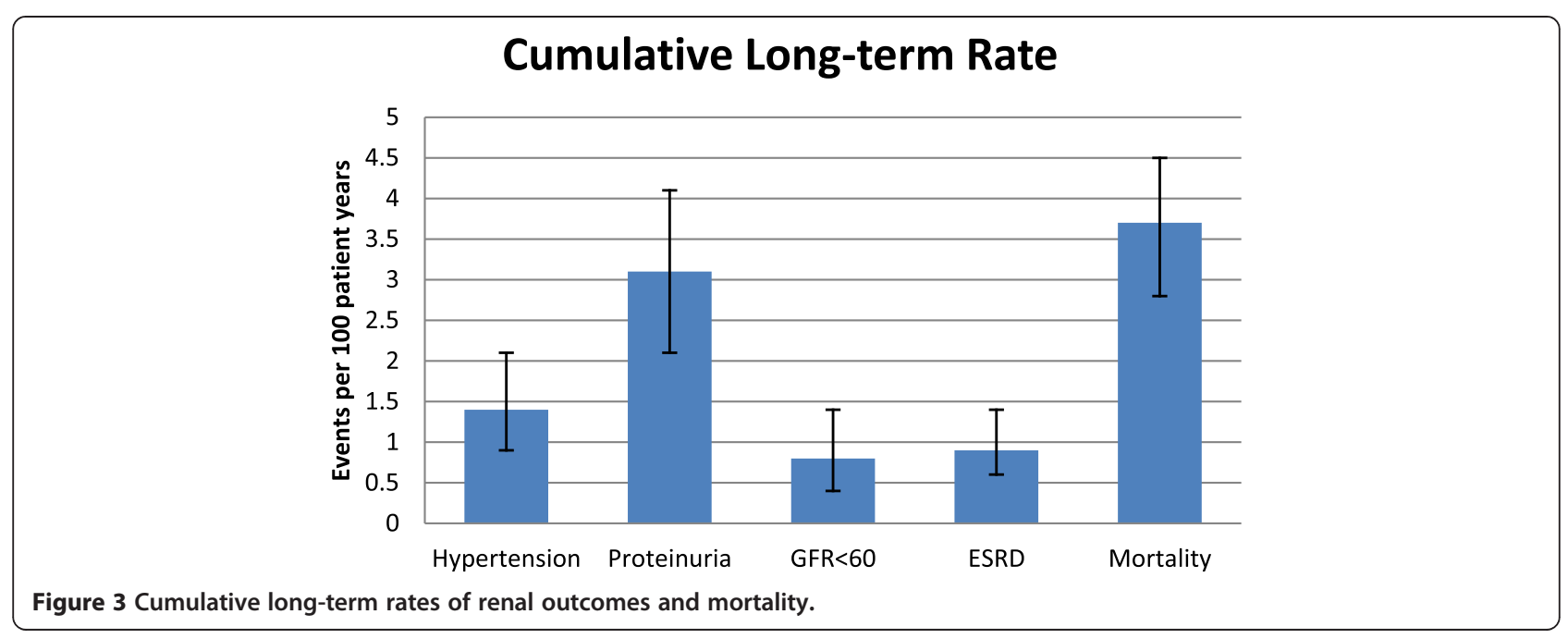

100 patient-years (range 0.98-43.7) respectively [20]. This higher rate of outcomes in adults can be somewhat attributed to the greater prevalence of comorbid risk factors of ESRD such as CKD, diabetes, and heart failure in the adult population. At the index hospitalization approximately $1 / 3$ of patients have CKD, $1 / 3$ to $1 / 2$ have diabetes, and $1 / 3$ have heart failure in the adult AKI cohorts [19,21-23,25]. In addition, as we observed in pediatric cohorts, the etiology of AKI in adults is most commonly due to complications of a surgery or hospitalization, not primary kidney disease. Despite the tremendous growth of AKI clinical research over the past decade, clinical studies in children and adults have yet to establish that preventing an episode of AKI decreases the risk of development of CKD and premature mortality.

One of the long-term outcomes evaluated in the primary studies was a GFR between 60 and $90 \mathrm{ml} / \mathrm{min} / 1.73 \mathrm{~m}^{2}$. In this review we estimated that this outcome was almost seven times more likely than a GFR $<60 \mathrm{ml} / \mathrm{min} / 1.73 \mathrm{~m}^{2}$. The clinical significance of having a GFR between 60 and $90 \mathrm{ml} / \mathrm{min} / 1.73 \mathrm{~m}^{2}$ comes into question especially when it is estimated using the imprecise Schwartz formula. Use of the new bedside CKiD equation would likely have differing results as it has been shown to improve the accuracy of estimating GFR in children with CKD [31]. Even if an eGFR of $60-90 \mathrm{ml} / \mathrm{min} / 1.73 \mathrm{~m}^{2}$ represents a true defect in glomerular filtration after the AKI, it is unclear whether this is a fixed abnormality of no clinical consequence or an abnormality that will progress to CKD and ESRD. The limited data from this review highlights this clinical uncertainty as no increased rates of abnormal GFR were found with increasing follow-up time. Moreover, it reinforces the need for research with a longer length of follow-up. A longer follow-up time will be beneficial, because even if it takes 25 years to manifest CKD after AKI, this would be clinically meaningful for a child who can have an additional 75 years of life expectancy after their AKI.

Two of the primary studies included hyperfiltration, or a GFR $>150 \mathrm{ml} / \mathrm{min} / 1.73 \mathrm{~m}^{2}$, as an outcome measure [14,41]. We did not include hyperfiltration in our results as this clinical parameter is not used to identify patients at risk for CKD or diagnose CKD in clinical practice guidelines such as Kidney Disease Improving Global Outcomes (KDIGO) and Kidney Disease Outcomes Quality Initiative (KDOQI) [27,42]. Hyperfiltration's significance as a marker of kidney dysfunction and a predictor of GFR decline after pediatric AKI is unclear and has not been validated in a pediatric cohort [43].

The topic of long-term outcomes after pediatric AKI is attracting more focus from the medical community as children with chronic disease are living longer and possibly at risk for recurrent episodes of AKI. Although there has been no systematic review performed on this topic previously, a similar review and meta-analysis was performed on children after hemolytic uremic syndrome. Garg et al. studied long-term renal outcomes after Hemolytic Uremic Syndrome and estimated that the rate of GFR $<80 \mathrm{ml} / \mathrm{min} / 1.73 \mathrm{~m}^{2}$ was 5.7 per 100 patient years, ESRD was 0.7 per 100 patient years, and mortality was 2.0 per 100 patient years [13]. In our systematic review the rate of abnormal GFR was 6.3, ESRD was 0.9, and mortality was 3.7 per 100 patient years.

While our review compels us to look closer at AKI as a risk factor for CKD in children, there were certain limitations to our results. First, $44 \%$ of patients included in these follow-up studies required renal replacement therapy during the index hospitalization for AKI. This is a higher percentage than is typically encountered in a cohort of pediatric AKI patients. More patients with severe AKI could have biased our results towards a higher cumulative incidence rate of renal dysfunction. There were also 
six distinct definitions of AKI used in the 10 different studies with some studies including only patients who required dialysis and others including any patient that had a $0.3 \mathrm{mg} / \mathrm{dL}$ increase in serum creatinine. The substantial difference between different AKI definitions could clearly affect the results in individual studies. Unfortunately a sensitivity analysis, where we stratified by AKI severity, was not feasible due to the small number of primary studies. Furthermore, many of the primary studies did not distinguish pre-renal causes of AKI from renal causes, including patients with any type of AKI and grouping them together. An AKI from volume depletion with a transient $0.3 \mathrm{mg} / \mathrm{dl}$ change in serum creatinine is less likely to have long-term sequelae as compared with an AKI from acute tubular necrosis. In order to definitively validate the long-term effects of AKI, standard definitions of AKI and CKD need to be uniformly adopted and used consistently in long-term studies [27,42].

The primary studies included in this review have substantial differences of methodological quality with regards to selection of patients, loss to follow-up, and reporting of outcomes. We see that some studies report a high incidence of CKD after AKI and others reported none. One of the potential explanations for this variability is the differences in outcome definitions. The two studies by Shaw et al. and Georgaki-Angelaki et al. found no evidence of proteinuria using urine dipstick testing whereas studies by Askenazi et al. and Mammen et al. found a much higher incidence of proteinuria when using the more sensitive test for microalbuminiuria $[14,41,44,45]$. On the other hand, Viaud et al. used a higher threshold test of a urine protein to creatinine ratio greater than $0.5 \mathrm{mg} / \mathrm{mg}$ to define proteinuria and found a $54 \%$ incidence [46]. This higher proportion of proteinuria may be attributed to the small sample size and a longer median follow-up time of 16 years. In addition, hypertension was diagnosed in some studies at one office visit whereas others required three separate visits for this diagnosis. Differing outcome definitions and methods of ascertainment highlight the importance of adhering to international consensus definitions when designing clinical studies. Due to this inter-study variability our pooled results should be interpreted carefully.

Other limitations of this study include small sample sizes and high rates of loss to follow-up. The latter may have introduced attrition bias, as the sicker population may be more likely to maintain contact with their physicians. These sicker patients may have inflated our calculated outcomes and led us to overestimate the amount of renal dysfunction after AKI.

With an increasing awareness of the long-term outcomes after AKI, more research needs to be performed. It remains to be determined whether all patients with AKI need to monitored or just those with more severe or prolonged AKI.
Monitoring for renal outcomes would be relatively simple, likely involving a blood pressure check, a urine dip, and a serum creatinine. CKD-related complications such as proteinuria or hypertension could then be treated with a renin-angiotensin-aldosterone antagonist such as an ACEinhibitor or an angiotensin receptor blocker. Primary care providers will likely become more involved with CKD screening as more children with chronic medical diseases are surviving their AKI and living longer.

\section{Conclusions}

AKI appears to be associated with a higher risk of longterm renal and non-renal outcomes in children as compared with the general pediatric population. However, the variation in renal outcomes between primary studies was sufficiently large to advise caution before interpreting these findings. Additional research will be needed to more accurately calculate rates of long-term outcomes after AKI. The different outcome definitions used by primary studies underscore the importance of adhering to KDIGO AKI and CKD guidelines when defining clinical outcomes in future studies $[27,47]$. Future research should include control groups where hospitalized patients without AKI are followed for renal sequelae. The lack of control groups in the primary studies clearly demonstrates a gap in the literature. Ongoing prospective long-term follow-up studies by the TRIBE-AKI (Translational Research Investigating Biomarker End-Points) consortium and the ASSESS-AKI Study (Assessment, Serial Evaluation, and Subsequent Sequelae of Acute Kidney Injury) was designed with control groups and should help to better define longterm outcomes after AKI in children [48-52]. In addition, there is a growing effort to study long-term AKI outcomes in neonates which was a focus of the NIH-sponsored Neonatal Acute Kidney Injury Workshop on April 9, 2013. A better understanding of pediatric AKI should provide opportunities for novel therapies and should direct the evolving guidelines of post-AKI outpatient management.

\section{Additional file}

Additional file 1: Search Strategy.

Competing interests

The authors declare that they have no competing interests.

\section{Authors' contributions}

JG participated in design of the study, performed the statistical analysis, and drafted the manuscript. SC participated in design of the study and helped to draft the manuscript. CP conceived of the study, participated in design of the study, and helped to draft the manuscript. All authors read and approved the final manuscript.

\section{Acknowledgements}

The authors thank Mark Gentry, Yale University School of Medicine Library, for his assistance with our search of the medical literature. 


\section{Support}

Dr. Greenberg is funded by the T32DK007276-35 training grant to the section of Nephrology.

Dr. Parikh was supported by the $\mathrm{NHH}$ grant RO1HL085757 and NIH grant K24DK090203. Dr. Parikh and Dr. Coca are members of the NIH-sponsored Assess, Serial Evaluation, and Subsequent Sequelae in Acute Kidney Injury (ASSESS-AKI) Consortium (U01DK082185)

\section{Author details}

'Department of Pediatrics, Section of Nephrology, Yale University School of Medicine, New Haven, CT, USA. ${ }^{2}$ Department of Internal Medicine, Section of Nephrology, New Haven, CT and VA Medical Center, Yale University School of Medicine, West Haven, CT, USA. ${ }^{3}$ Yale Program of Applied Translational Research, Yale University School of Medicine, 60 Temple Street, 6th Floor, Suite 6C, New Haven 06510, CT, USA.

Received: 27 June 2014 Accepted: 3 November 2014 Published: 21 November 2014

\section{References}

1. Vachvanichsanong P, Dissaneewate $P$, Lim A, McNeil E: Childhood acute renal failure: 22-year experience in a university hospital in southern Thailand. Pediatrics 2006, 118(3):e786-e791.

2. Lesi ALT: Paediatric kidney diseases in an African country: Prevalence, Spectrum and Outcome. Saudi J Kidney Dis 2013, 25(5):1110-1116.

3. Hui-Stickle S, Brewer ED, Goldstein SL: Pediatric ARF epidemiology at a tertiary care center from 1999 to 2001. Am J Kidney Dis 2005, 45(1):96-101.

4. Ball EF, Kara T: Epidemiology and outcome of acute kidney injury in New Zealand children. J Paediatr Child Health 2008, 44(11):642-646.

5. Williams DM, Sreedhar SS, Mickell JJ, Chan JC: Acute kidney failure: a pediatric experience over 20 years. Arch Pediatr Adolesc Med 2002, 156(9):893-900.

6. Bailey D, Phan V, Litalien C, Ducruet T, Merouani A, Lacroix J, Gauvin F: Risk factors of acute renal failure in critically ill children: A prospective descriptive epidemiological study. Pediatr Crit Care Med 2007, 8(1):29-35.

7. Loza R, Estremadoyro L, Loza C, Cieza J: Factors associated with mortality in acute renal failure (ARF) in children. Pediatr Nephrol 2006, 21(1):106-109.

8. Sutherland SM, Ji J, Sheikhi FH, Widen E, Tian L, Alexander SR, Ling XB: AKI in Hospitalized Children: Epidemiology and Clinical Associations in a National Cohort. Clin J Am Soc Nephrol 2013, 8:1661-1669.

9. Imani PD, Odiit A, Hingorani SR, Weiss NS, Eddy AA: Acute kidney injury and its association with in-hospital mortality among children with acute infections. Pediatr Nephrol 2013, 28(11):2199-2206.

10. Chertow GM, Levy EM, Hammermeister KE, Grover F, Daley J: Independent association between acute renal failure and mortality following cardiac surgery. Am J Med 1998, 104(4):343-348.

11. Uchino S, Kellum JA, Bellomo R, Doig GS, Morimatsu H, Morgera S, Schetz M, Tan I, Bouman C, Macedo E, Gibney N, Tolwani A, Ronco C: Acute renal failure in critically ill patients: a multinational, multicenter study. JAMA 2005, 294(7):813-818.

12. Basile DP: Rarefaction of peritubular capillaries following ischemic acute renal failure: a potential factor predisposing to progressive nephropathy. Curr Opin Nephrol Hypertens 2004, 13(1):1-7.

13. Garg AX, Suri RS, Barrowman N, Rehman F, Matsell D, Rosas-Arellano MP, Salvadori M, Haynes RB, Clark WF: Long-term renal prognosis of diarrheaassociated hemolytic uremic syndrome: a systematic review, meta-analysis, and meta-regression. JAMA 2003, 290(10):1360-1370.

14. Askenazi DJ, Feig DI, Graham NM, Hui-Stickle S, Goldstein SL: 3-5 year longitudinal follow-up of pediatric patients after acute renal failure. Kidney Int 2006, 69(1):184-189.

15. Basile DP, Donohoe DL, Roethe K, Mattson DL: Chronic renal hypoxia after acute ischemic injury: effects of L-arginine on hypoxia and secondary damage. Am J Physiol Renal Physiol 2003, 284(2):F338-F348.

16. Yang L, Besschetnova TY, Brooks CR, Shah JV, Bonventre JV: Epithelial cell cycle arrest in G2/M mediates kidney fibrosis after injury. Nature medicine 2010, 16(5):535-543. 531p following 143

17. Lewers DT, Mathew TH, Maher JF, Schreiner GE: Long-term follow-up of renal function and histology after acute tubular necrosis. Ann Intern Med 1970, 73(4):523-529.
18. Kjellstrand CM, Ebben J, Davin T: Time of death, recovery of renal function, development of chronic renal failure and need for chronic hemodialysis in patients with acute tubular necrosis. Trans Am Soc Artif Intern Organs 1981, 27:45-50.

19. Amdur RL, Chawla LS, Amodeo S, Kimmel PL, Palant CE: Outcomes following diagnosis of acute renal failure in U.S. veterans: focus on acute tubular necrosis. Kidney Int 2009, 76(10):1089-1097.

20. Coca SG, Singanamala S, Parikh CR: Chronic kidney disease after acute kidney injury: a systematic review and meta-analysis. Kidney Int 2012, 81(5):442-448.

21. Lo LJ, Go AS, Chertow GM, McCulloch CE, Fan D, Ordonez JD, Hsu CY: Dialysis-requiring acute renal failure increases the risk of progressive chronic kidney disease. Kidney Int 2009, 76(8):893-899.

22. Chawla LS, Amdur RL, Amodeo S, Kimmel PL, Palant CE: The severity of acute kidney injury predicts progression to chronic kidney disease. Kidney Int 2011, 79(12):1361-1369.

23. Wald R, Quinn RR, Luo J, Li P, Scales DC, Mamdani MM, Ray JG, University of Toronto Acute Kidney Injury Research G: Chronic dialysis and death among survivors of acute kidney injury requiring dialysis. JAMA 2009, 302(11):1179-1185.

24. Ando M, Ohashi K, Akiyama H, Sakamaki H, Morito T, Tsuchiya K, Nitta K: Chronic kidney disease in long-term survivors of myeloablative allogeneic haematopoietic cell transplantation: prevalence and risk factors. Nephrol Dial Transplant 2010, 25(1):278-282.

25. Ishani A, Nelson D, Clothier B, Schult T, Nugent S, Greer N, Slinin Y, Ensrud KE: The magnitude of acute serum creatinine increase after cardiac surgery and the risk of chronic kidney disease, progression of kidney disease, and death. Arch Intern Med 2011, 171(3):226-233.

26. Askenazi DJ: Do children with acute kidney injury require long-term evaluation for CKD? Am J Kidney Dis 2012, 59(4):478-480.

27. Kidney Disease: Improving Global O: KDIGO 2012 Clinical Practice Guideline for the Evaluation and Management of Chronic Kidney Disease. Kidney Intern Supp/ 2013, 3(1):1-163.

28. Lozano R, Naghavi M, Foreman K, Lim S, Shibuya K, Aboyans V, Abraham J, Adair T, Aggarwal R, Ahn SY, Alvarado M, Anderson HR, Anderson LM, Andrews KG, Atkinson C, Baddour LM, Barker-Collo S, Bartels DH, Bell ML, Benjamin EJ, Bennett D, Bhalla K, Bikbov B, Bin Abdulhak A, Birbeck G, Blyth F, Bolliger I, Boufous S, Bucello C, Burch M, et al: Global and regional mortality from 235 causes of death for 20 age groups in 1990 and 2010: a systematic analysis for the Global Burden of Disease Study 2010. Lancet 2012, 380(9859):2095-2128.

29. Goldstein SL: Acute kidney injury in children and its potential consequences in adulthood. Blood Purif 2012, 33(1-3):131-137.

30. Higgins JPT AD: Assessing risk of bias in included studies. In Cochrane Handbook for Systematic Reviews of Interventions. Volume Version 5.0.1. Edited by Higgins JPT GS. The Cochrane Collaboration; 2008. Available from www. cochrane-handbook.org.

31. Schwartz GJ, Munoz A, Schneider MF, Mak RH, Kaskel F, Warady BA, Furth SL: New equations to estimate GFR in children with CKD. J Am Soc Nephrol 2009, 20(3):629-637.

32. Schwartz GJ, Haycock GB, Edelmann CM Jr, Spitzer A: A simple estimate of glomerular filtration rate in children derived from body length and plasma creatinine. Pediatrics 1976, 58(2):259-263.

33. Mattman A, Eintracht S, Mock T, Schick G, Seccombe DW, Hurley RM, White $\mathrm{CT}$ : Estimating pediatric glomerular filtration rates in the era of chronic kidney disease staging. J Am Soc Nephrol 2006, 17(2):487-496.

34. van Rossum LK, Mathot RA, Cransberg K, Zietse R, Vulto AG: Estimation of the glomerular filtration rate in children: which algorithm should be used? Pediatr Nephrol 2005, 20(12):1769-1775.

35. Schwartz GJ, Work DF: Measurement and estimation of GFR in children and adolescents. Clin J Am Soc Nephrol 2009, 4(11):1832-1843.

36. Mel EDM, Dagan O: Long-term follow-up evaluation of renal function in patients treated with peritoneal dialysis after cardiac surgery for correction of congenital anomalies. J Thorac Cardiovasc Surg 2013, 147(1):451-455.

37. Miler M: Acute renal failure in children and its long-term follow-up treatment. Med Sci Monit 1997, 3(4):563-572.

38. Ginsberg JP, Goodman P, Leisenring W, Ness KK, Meyers PA, Wolden SL, Smith SM, Stovall M, Hammond S, Robison LL, Oeffinger KC: Long-term survivors of childhood Ewing sarcoma: report from the childhood cancer survivor study. J Natl Cancer Inst 2010, 102(16):1272-1283. 
39. Butt W, Shann F, Tibballs J, Williams J, Cuddihy L, Blewett L, Farley M: Long-term outcome of children after intensive care. Crit Care Med 1990, 18(9):961-965.

40. Arias E: United States life tables, 2009. Natl Vital Stat Rep 2014, 62(7):1-63.

41. Mammen C, Al Abbas A, Skippen P, Nadel H, Levine D, Collet JP, Matsell DG: Long-term risk of CKD in children surviving episodes of acute kidney injury in the intensive care unit: a prospective cohort study. Am J Kidney Dis 2012, 59(4):523-530.

42. Hogg RJ, Furth S, Lemley KV, Portman R, Schwartz GJ, Coresh J, Balk E, Lau J, Levin A, Kausz AT, Eknoyan G, Levey AS: National Kidney Foundation's Kidney Disease Outcomes Quality Initiative clinical practice guidelines for chronic kidney disease in children and adolescents: evaluation, classification, and stratification. Pediatrics 2003, 111(6 Pt 1):1416-1421.

43. Brenner BM, Lawler EV, Mackenzie HS: The hyperfiltration theory: a paradigm shift in nephrology. Kidney Int 1996, 49(6):1774-1777.

44. Shaw NJ, Brocklebank JT, Dickinson DF, Wilson N, Walker DR: Long-term outcome for children with acute renal failure following cardiac surgery. Int J Cardiol 1991, 31(2):161-165.

45. Georgaki-Angelaki HN, Steed DB, Chantler C, Haycock GB: Renal function following acute renal failure in childhood: a long term follow-up study. Kidney Int 1989, 35(1):84-89.

46. Viaud M, Llanas B, Harambat J: Renal outcome in long-term survivors from severe acute kidney injury in childhood. Pediatr Nephrol 2012, 27(1):151-152. author reply 153.

47. Kellum JA, Lameire N, for the KAKIGWG: Diagnosis, evaluation, and management of acute kidney injury: a KDIGO summary (Part 1). Crit Care 2013, 17(1):204.

48. Go AS, Parikh CR, Ikizler TA, Coca S, Siew ED, Chinchilli VM, Hsu CY, Garg AX, Zappitelli M, Liu KD, Reeves WB, Ghahramani N, Devarajan P, Faulkner GB, Tan TC, Kimmel PL, Eggers P, Stokes JB: The assessment, serial evaluation, and subsequent sequelae of acute kidney injury (ASSESS-AKI) study: design and methods. BMC Nephrol 2010, 11:22.

49. Coca SG, Garg AX, Thiessen-Philbrook H, Koyner JL, Patel UD, Krumholz HM, Shlipak MG, Parikh CR, for the T-AKIC: Urinary Biomarkers of AKI and Mortality 3 Years after Cardiac Surgery. J Am Soc Nephrol 2013, 25(5):1063-1071.

50. Buysse CM, Raat H, Hazelzet JA, Hulst JM, Cransberg K, Hop WC, Vermunt LC, Utens EM, Maliepaard M, Joosten KF: Long-term health status in childhood survivors of meningococcal septic shock. Arch Pediatr Adolesc Med 2008, 162(11):1036-1041

51. Slack R, Hawkins KC, Gilhooley L, Addison GM, Lewis MA, Webb NJ: Long-term outcome of meningococcal sepsis-associated acute renal failure. Pediatr Crit Care Med 2005, 6(4):477-479.

52. Wedekin M, Ehrich JH, Offner G, Pape L: Aetiology and outcome of acute and chronic renal failure in infants. Nephrol Dial Transplant 2008, 23(5):1575-1580.

doi:10.1186/1471-2369-15-184

Cite this article as: Greenberg et al:: Long-term risk of chronic kidney disease and mortality in children after acute kidney injury: a systematic review. BMC Nephrology 2014 15:184.

\section{Submit your next manuscript to BioMed Central and take full advantage of:}

- Convenient online submission

- Thorough peer review

- No space constraints or color figure charges

- Immediate publication on acceptance

- Inclusion in PubMed, CAS, Scopus and Google Scholar

- Research which is freely available for redistribution

Submit your manuscript at www.biomedcentral.com/submit
C Biomed Central 